\title{
Test-Retest Reliability and Consistency of Electronic Jammar Hand-Grip Dynamometer in Cricket Players
}

\author{
Pavan KumarT ${ }^{1}$., Sivachidambaram Kulandaivelan ${ }^{2}$., Anuja Yadav ${ }^{3}$., \\ Pola Vasu ${ }^{4}$. \\ ${ }^{I}$ Team Physiotherapist, UP Ranji Team, UPCA, Kanpur- 208 005, UP, India \\ ${ }^{2}$ Assistant Professor, Dept. Of Physiotherapy, GJUST, Hisar-125 001. Haryana. India \\ ${ }^{3}$ Clinical Physiotherapist, New Delhi \\ ${ }^{4}$ Clinical Physiotherapist, Sai Sri Advanced Physiotherapy Clinic, Tirupati. AP. India
}

\begin{abstract}
Handgrip strength plays a important role in cricket as various roles played in cricket rely on the continuous use of wrist and digits flexor muscles when catching, holding bat and ball, throwing the ball. Therefore, the assessment of handgrip strength is used in 31 cricket players. The purpose of this study was to examine the reliability of handgrip strength in cricket players. Each participant performed three maximal isometric contractions in six different positions on each hand for two occasions, at least one day apart. Intraclass correlation coefficient (ICC)- (Single-Pearson's correlation coefficient ( $r$ ) and Average-Cronbach's alpha)- with 95\% CI were calculated. Internal consistency (Cronbach's alpha) was excellent (0.956-0.982 for right and 0.956-0.984 for left). The test-retest reliability (Pearson's ' $r$ ') was high for both right (0.743- 0.856) and left (ICC $=0.781-0.899)$ hands. The present results indicate that maximum handgrip strength can be measured reliably, using the Jamar hand dynamometer, in cricket players.
\end{abstract}

Keywords: Batsmen, Bowlers, All-rounders, Wicket-keepers, ICC, Cronbach's alpha

\section{Introduction}

The estimation of handgrip strength is of immense importance in sports like cricket, wrestling, tennis, football, handball, basketball, volleyball, and baseball where a sufficient degree of grip strength is necessary to be successful play (Koley and Kaur, 2011). In cricket, hand-grip plays a significant contribution in roles (i.e) Batting, bowling and fielding.

Grip strength plays a key role in injury prevention and overall strength development (Budoff, 2004; Yasuo et al., 2005). Grip strength is often used as an indicator of overall physical strength (Foo, 2007), hand and forearm muscles performances (Nwuga, 1975) and as a functional index of nutritional status (Chilima and Ismail, 2001; Pieterse et al., 2002; Wang et al., 2005), physical performance (Samson et al., 2000; Onder et al., 2002).

Hand-grip dynamometers measures hand grip based on 4 principles: sealed hydraulic system (Hydraulic), compression of an air-filled compartment (Pneumatic), amount of tension produced in a spring (mechanical), variation in electrical resistance of length of wire (Strain) (Roberts et al., 2011). Jammar dynamometer uses hydraulic principle and widely used in literature. Recently Jammar dynamometers are produced in electronic format which reliability, consistency has not checked.

Thus purpose of this paper is to check the internal consistency, test-retest reliability of electronic Jammar hand-grip dynamometer in Indian cricket players of 18-25 years. Then discuss the results with literature.

\section{Methodology}

Present study was a cross sectional study with convenient sample of 37 cricket players. The inclusion criteria were male cricket players with experience of at least two years training and played at least district level. Player age should be 18 or more. Players with following conditions were excluded from the study: Not trained in last 2 months due to any injury or illness, having musculoskeletal injuries in upper limb which may affect hand-grip, cervical pain, any neurological injury. All players were representing a club in Hisar, Haryana and gave their verbal informed consent to participate the study.

All players were asked to come two times $\left(1^{\text {st }}\right.$ and $2^{\text {nd }}$ visit $)$ with at least one day gap and maximum of three days from initial assessment. Demonstration was given to each player on how to hold each position. There was total of six positions for both right and left hand. The six positions were P1- Shoulder adducted, elbow extended, forearm supinated; P2- Shoulder adducted, elbow extended, forearm pronated; P3- Shoulder adducted, elbow flexed 90 degree, forearm in mid pronation; P4- Shoulder 90 degree abducted, externally rotated, elbow 90 degree flexed, forearm pronated; P5- Shoulder 170-180 degree flexed, externally rotated, elbow 20 degree 
flexed, forearm pronated; P6- Shoulder 20-30 degree flexion, 20-30 degree abduction, medially rotated, elbow 90 degree flexed, forearm pronated; in all positions wrist was slightly extended. 3 trials were given for each position and one minute rest was given between the trials. Instruction given for grip measurement was "Bring your fingers towards $1^{\text {st }}$ web base/palm with as hard as possible.....harder.....harder.....relax".

Electronic Jammar hand-grip dynamometer [Jammar Plus, Sammons Preston, Bolingbrook, IL] was used to assess hand-grip. It has five handle positions which can be adjusted according to the span of hand. We used second handle as this is universally used in literature.

The data collected was analysed using IBM SPSS (20.0 version) software. Data was presented as mean \pm SD. Unrelated ' $\mathrm{t}$ ' test was used to see the difference between $1^{\text {st }}$ and $2^{\text {nd }}$ time hand-grip mean. Intraclass correlation coefficient (ICC) was used for both consistency (Cronbach's alpha) and reliability (Pearson's correlation) with $95 \% \mathrm{CI}$ (confidence interval).

\section{Results}

Table 1 shows mean measurement of $1^{\text {st }}$ and $2^{\text {nd }}$ time in right side. P6 (Shoulder medially rotatedbatting position) has the least grip-strength $\left(43.70 \mathrm{Kg}\right.$ in $2^{\text {nd }}$ time) and P1 (Shoulder adducted, elbow extended and forearm supinated) has maximum grip strength $\left(49.33 \mathrm{Kg}\right.$ in $1^{\text {st }}$ time) in right side of cricket players. $1^{\text {st }}$ time measurement has always greater than $2^{\text {nd }}$ time without significant difference. Mean difference is less than $3 \%$ higher than $2^{\text {nd }}$ time.

Table 1: Comparison of two measurements in right side with Jammar dynamometer

\begin{tabular}{|l|l|l|l|}
\hline & $\begin{array}{l}\text { Mean } \pm \text { SD of } 1^{\text {st }} \\
\text { measurement }\end{array}$ & $\begin{array}{l}\text { Mean } \pm \text { SD of } 2^{\text {nd }} \\
\text { measurement }\end{array}$ & $\begin{array}{l}\text { Mean difference } \\
(\mathrm{p} \text { value })\end{array}$ \\
\hline RJP1 & $49.33 \pm 6.96$ & $48.88 \pm 8.41$ & $0.453(0.809)$ \\
\hline RJP2 & $46.78 \pm 6.92$ & $45.25 \pm 8.29$ & $1.539(0.407)$ \\
\hline RJP3 & $48.64 \pm 7.12$ & $46.59 \pm 8.43$ & $2.046(0.282)$ \\
\hline RJP4 & $48.37 \pm 6.76$ & $46.47 \pm 8.72$ & $1.904(0.314)$ \\
\hline RJP5 & $47.04 \pm 7.28$ & $45.99 \pm 8.26$ & $1.054(0.578)$ \\
\hline RJP6 & $45.13 \pm 6.98$ & $43.70 \pm 7.97$ & $1.432(0.433)$ \\
\hline
\end{tabular}

Table 2: Comparison of two measurements in left side with Jammar dynamometer

\begin{tabular}{|l|l|l|l|}
\hline & $\begin{array}{l}\text { Mean } \pm \text { SD of } 1^{\text {st }} \\
\text { measurement }\end{array}$ & $\begin{array}{l}\text { Mean } \pm \text { SD of } 2^{\text {nd }} \\
\text { measurement }\end{array}$ & $\begin{array}{l}\text { Mean difference } \\
(\mathrm{p} \text { value) }\end{array}$ \\
\hline LJP1 & $46.60 \pm 8.35$ & $45.82 \pm 8.54$ & $0.775(0.707)$ \\
\hline LJP2 & $44.83 \pm 7.95$ & $42.31 \pm 7.79$ & $2.528(0.192)$ \\
\hline LJP3 & $46.09 \pm 7.75$ & $43.37 \pm 7.75$ & $2.714(0.155)$ \\
\hline LJP4 & $45.54 \pm 7.57$ & $42.97 \pm 7.43$ & $2.582(0.163)$ \\
\hline LJP5 & $44.71 \pm 7.48$ & $42.48 \pm 7.63$ & $2.229(0.229)$ \\
\hline LJP6 & $42.72 \pm 6.86$ & $41.58 \pm 7.16$ & $1.140(0.506)$ \\
\hline
\end{tabular}

Table 2 shows mean measurement of $1^{\text {st }}$ and $2^{\text {nd }}$ time in left side. Left side grip-strength values are less than that of right side in all six positions. Like right side, left side too P6 position (Shoulder medially rotatedbatting position) has the least grip-strength $\left(41.58 \mathrm{Kg}\right.$ in $2^{\text {nd }}$ time) and P1 (Shoulder adducted, elbow extended and forearm supinated) has maximum grip strength $\left(46.60 \mathrm{Kg}\right.$ in $1^{\text {st }}$ time $)$ in cricket players. $1^{\text {st }}$ time measurement has always greater than $2^{\text {nd }}$ time without significant difference. Mean difference is less than $5 \%$ higher than $2^{\text {nd }}$ time.

Table 3 shows that internal consistency (Cronbach's alpha) of right side in both $1^{\text {st }}$ and $2^{\text {nd }}$ visits for all six positions with $95 \%$ CI. There was an excellent consistency in both $1^{\text {st }}$ visits $(0.956-0.975)$ and $2^{\text {nd }}$ visits (0.969-0.982). Internal consistency was maximum in P3 position (traditional-Shoulder adducted. Elbow flexed 90 degree, forearm midpronation) and least in P4 position (Shoulder abducted 90 degree, externally rotated, elbow flexed 90 degree, forearm pronated) for both $1^{\text {st }}$ and $2^{\text {nd }}$ visits.

Table 3: Internal consistency ( 3 trials each visit) of Jammar dynamometer at right side.

\begin{tabular}{|l|l|l|l|l|l|l|}
\hline Position & \multicolumn{2}{|l|}{$\mathbf{1}^{\text {st }}$ visit measurement $(\mathbf{n}=37)$} & \multicolumn{2}{l|}{$\mathbf{2}^{\text {nd }}$ visit measurement $(\mathbf{n}=\mathbf{3 1})$} \\
\hline & Single & Average & $95 \%$ CI of average & Single & Average & 95\% CI of average \\
\hline RJP1 & 0.901 & 0.964 & $0.938-0.980$ & 0.918 & 0.971 & $0.948-0.985$ \\
\hline RJP2 & 0.906 & 0.965 & $0.939-0.981$ & 0.939 & 0.977 & $0.957-0.988$ \\
\hline RJP3 & 0.931 & 0.975 & $0.956-0.986$ & 0.950 & 0.982 & $0.968-0.991$ \\
\hline RJP4 & 0.880 & 0.956 & $0.924-0.976$ & 0.914 & 0.969 & $0.944-0.984$ \\
\hline RJP5 & 0.919 & 0.968 & $0.944-0.982$ & 0.941 & 0.980 & $0.964-0.990$ \\
\hline RJP6 & 0.889 & 0.960 & $0.930-0.978$ & 0.934 & 0.975 & $0.954-0.987$ \\
\hline
\end{tabular}

Single also known ICC (Single) or average of Pearson's correlation (r), Average also known as ICC (Average) or Cronbach's alpha 
Table 4: Test-retest reliability of Jammar dynamometer at right side $(\mathrm{n}=31)$

\begin{tabular}{|l|l|l|l|l|}
\hline & ICC (Single) & 95\% CI of ICC & Cronbach's Alpha & 95\% CI of Cronbach's Alpha \\
\hline RJP1 & 0.768 & $0.573-0.881$ & 0.869 & $0.728-0.937$ \\
\hline RJP2 & 0.743 & $0.532-0.867$ & 0.853 & $0.695-0.929$ \\
\hline RJP3 & 0.764 & $0.565-0.879$ & 0.866 & $0.722-0.935$ \\
\hline RJP4 & 0.807 & $0.637-0.902$ & 0.893 & $0.778-0.948$ \\
\hline RJP5 & 0.786 & $0.602-0.891$ & 0.880 & $0.751-0.942$ \\
\hline RJP6 & 0.856 & $0.722-0.928$ & 0.922 & $0.839-0.962$ \\
\hline
\end{tabular}

ICC (single) also known as Pearson's correlation (r)

Table 4 shows test-retest $\left(1^{\text {st }}\right.$ and $2^{\text {nd }}$ visits mean) reliability of right side of cricket players in all six positions. The results showed there was a moderate to high correlation between $1^{\text {st }}$ and $2^{\text {nd }}$ visits hand-grip strength (0.743-0.856). The reliability was low in P2 position (shoulder adducted, elbow extended, forearm pronated) and maximum in P6 position (batting position-Shoulder 20 degree flexed, 20 degree abducted, internally rotated, elbow 90 degree flexed, forearm pronated). Correlation between $1^{\text {st }}$ and $2^{\text {nd }}$ visits right side hand-grip values is diagrammatically given in Figure 1 (for P1 to P3) and Figure 2 (P4 to P6). Line given in figures is linear regression fit line with R2 values.

Figure 1: Correlation matrix along with regression line between first and second visits readings in jammar position 1 to position 3 of right side $(\mathrm{n}=31)$

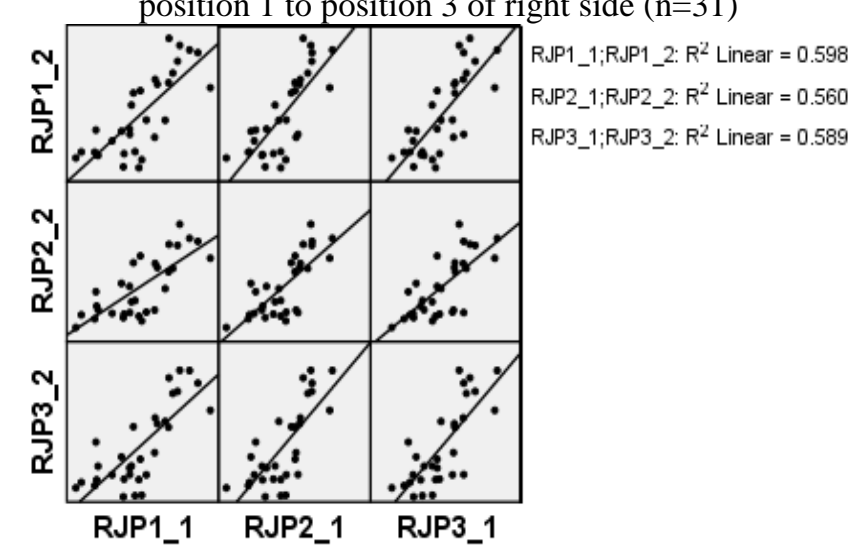

Figure 2: Correlation matrix along with regression line between first and second visits readings in jammar position 4 to position 6 of right side $(n=31)$

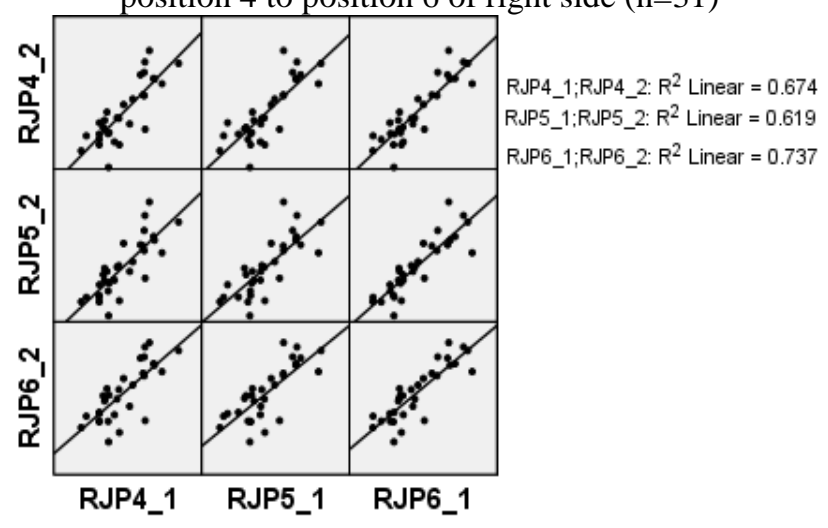

Table 5: Internal consistency (3 repeated measures) of Jamar dynamometer at left side

\begin{tabular}{|l|l|l|l|l|l|l|}
\hline Position & \multicolumn{3}{|l|}{ First measurement $\mathbf{( n = 3 7 )}$} & \multicolumn{3}{l|}{ Second measurement $\mathbf{( n = 3 1 )}$} \\
\hline & Single & Average & 95\% CI of average & Single & Average & 95\% CI of average \\
\hline LJP1 & 0.902 & 0.965 & $0.940-0.981$ & 0.928 & 0.975 & $0.954-0.987$ \\
\hline LJP2 & 0.953 & 0.984 & $0.972-0.991$ & 0.932 & 0.976 & $0.956-0.987$ \\
\hline LJP3 & 0.951 & 0.983 & $0.970-0.991$ & 0.922 & 0.972 & $0.950-0.986$ \\
\hline LJP4 & 0.880 & 0.956 & $0.924-0.976$ & 0.907 & 0.965 & $0.937-0.982$ \\
\hline LJP5 & 0.943 & 0.980 & $0.965-0.989$ & 0.899 & 0.963 & $0.932-0.981$ \\
\hline LJP6 & 0.905 & 0.966 & $0.941-0.981$ & 0.893 & 0.961 & $0.929-0.980$ \\
\hline
\end{tabular}

Single also known ICC (Single) or average of Pearson's correlation (r), Average also known as ICC (Average) or Cronbach's alpha 
Table 5 shows that internal consistency (Cronbach's alpha) of right side in both $1^{\text {st }}$ and $2^{\text {nd }}$ visits for all six positions with $95 \%$ CI. There was an excellent consistency in both $1^{\text {st }}$ visits $(0.956-0.984)$ and $2^{\text {nd }}$ visits (0.961-0.976). Internal consistency was maximum in P2 position (Shoulder adducted, elbow extended, forearm pronated) for both $1^{\text {st }}$ and $2^{\text {nd }}$ visits.

Table 4 shows test-retest $\left(1^{\text {st }}\right.$ and $2^{\text {nd }}$ visits mean) reliability of left side of cricket players in all six positions with $95 \%$ CI. The results showed there was a moderate to high correlation between $1^{\text {st }}$ and $2^{\text {nd }}$ visits hand-grip strength (0.781-0.899). The reliability was low in P6 position (Batting position- Shoulder 20 degree flexed, 20 degree abducted, internally rotated, elbow flexed 90 degree, forearm pronated) and maximum in P4 position (Throwing position- Shoulder 90 degree abducted, externally rotated, elbow 90 degree flexed, forearm pronated). Correlation between $1^{\text {st }}$ and $2^{\text {nd }}$ visits left side hand-grip values is diagrammatically given in Figure 3 (for P1 to P3) and Figure 4 (P4 to P6). Line given in figures is linear regression fit line with R2 values.

Table 6: Test-retest reliability of Jamar dynamometer at left side $(\mathrm{n}=31)$

\begin{tabular}{|l|l|l|l|l|}
\hline & ICC (Single) & $95 \%$ CI of ICC & Cronbach's Alpha & 95\% CI of Cronbach's Alpha \\
\hline LJP1 & 0.836 & $0.688-0.918$ & 0.911 & $0.815-0.957$ \\
\hline LJP2 & 0.861 & $0.731-0.930$ & 0.925 & $0.845-0.964$ \\
\hline LJP3 & 0.801 & $0.627-0.899$ & 0.890 & $0.771-0.947$ \\
\hline LJP4 & 0.899 & $0.801-0.950$ & 0.947 & $0.890-0.974$ \\
\hline LJP5 & 0.815 & $0.651-0.906$ & 0.898 & $0.788-0.951$ \\
\hline LJP6 & 0.781 & $0.593-0.888$ & 0.877 & $0.745-0.941$ \\
\hline
\end{tabular}

ICC (single) also known as Pearson's correlation (r)

Figure 3: Correlation matrix along with regression line between first and second readings in jammar position 1

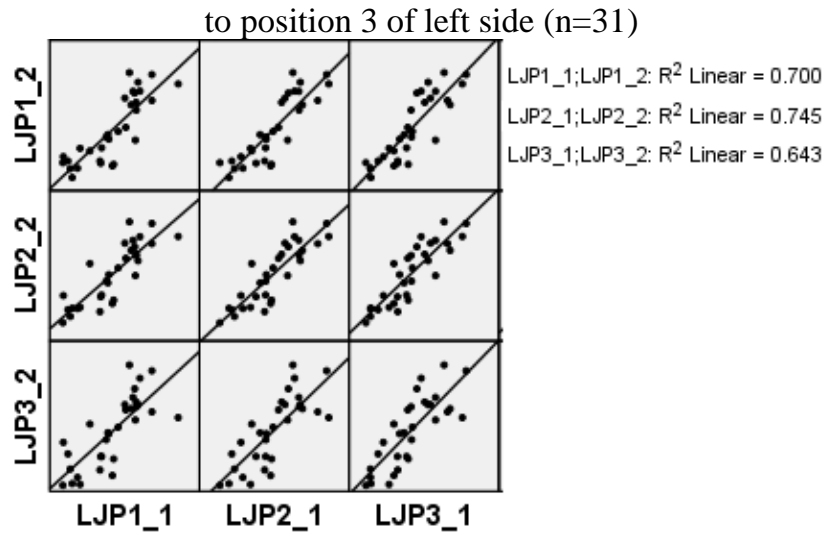

Figure 4: Correlation matrix along with regression line between first and second readings in jammar position 4

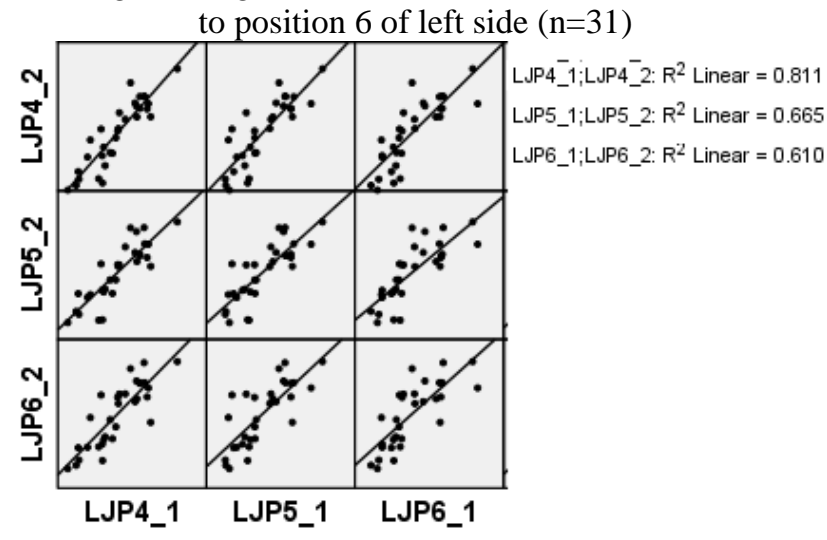

\section{Discussion}

The primary objective of this paper is consistency, reliability of electronic hand-grip dynamometer in cricket players in India. The results showed there is a excellent internal consistency and moderate reliability in electronic hand-grip dynamometer in Indian cricket players.

Measurements of grip strength taken with the Jamar dynamometer have evidence for good to excellent ( $\mathrm{r}>0.80)$ test-retest reproducibility [Mathiowetz et al., 1984; Haward and Griffin, 2002; Bohannon and Schaubert, 2005; Gerodimos, 2012; Gerodimos and Karatrantou, 2013] and excellent (r >0.94) intra-rater 
reliability, internal consistency [Gerodimos and Karatrantou, 2013; Lindstrom-Hazel et al., 2009; Trutschnigg et al., 2008; Peolsson et al., 2001]. Kolber and Cleland (2005) found the ICC of ratters testing participants without known impairments to be 0.52 to 0.93 when using hand-held dynamometry. In a review of 18 studies, Bohannon (1999) found the majority of reliability coefficients for hand-held dynamometry to be above 0.7 .

Among sportsmen, pubertal Wrestlers showed excellent internal consistency (correlation between 3 trials ranged 0.993-0.996) and test-retest reliability (ICC ranged 0.990-0.993) (Gerodimos and Karatrantou, 2013). Same author reported excellent test-retest reliability in adolescent and adult Basketball players too (ICC ranged in 0.971-0.997) (Gerodimos, 2012).

Peolsson et al., 2001 examined intra-tester reliability (internal consistency) on healthy volunteers and ranged 0.94-0.98. Trutschnigg et al., (2008) showed internal consistency of 0.996 on repeated measures in advanced cancer patients. Bohannon and Schaubert (2005) evaluated test-retest reliability of Jammar dynamometer on community dwelling elders over 12 weeks period. They found no difference between measurements and ICC of 0.954, 0.912 for right, left hand respectively. Haward and Griffin, (2002) examined the reliability of Jammar dynamometer on University students and employees for 3 successive weeks. Their results showed 'Spearman's Rho' 0.77 (week 1 and 2 on dominant hand) to 0.94 (week 2 and 3 on nondominant hand). Mathiowetz et al., 1984 studied the test-retest reliability of Jammar dynamometer on 27 University women over less than week period and their results showed 0.883 for right side and 0.929 for left side.

\section{Conclusion}

Electronic Jammar hand-grip dynamometer is consistent, reliable instrument on sports person especially cricket players. It can be used by physiotherapists in training, pre participation evaluation, rehabilitative (diagnostic and prognostic) settings.

\section{References}

[1]. Bohannon, R. W. 1999. Inter-tester reliability of hand-held dynamometry: A concise summary of published research. Perceptual and Motor Skills, 88:899-902.

[2]. Bohannon, R. W., Schaubert, K. L. 2005. Test-retest reliability of grip-strength measures obtained over a 12-week interval from community-dwelling elders. Journal of Hand Therapy, 18(4):426-28.

[3]. Budoff, J. E. 2004. The relevance of rotator cuff weakness in patients with injured hands. J Hand Surg, 29:1154-59.

[4]. Chilima, D. M., Ismail, S. J. 2001. Nutrition and hand grip strength of older adults in rural Malawi. Public Health Nutr, 9:11-17.

[5]. Foo, L. H. 2007. Influence of body composition, muscle strength, diet and physical activity on total body and forearm bone mass in Chinese adolescent girls. Br J Nutr, 98:1281-87.

[6]. Gerodimos, V. 2012. Reliability of handgrip strength test in Basketball players. Journal of Human Kinetics, 31:25-36.

[7]. Gerodimos, V., Karatrantou, K. 2013. Reliability of maximal handgrip strength test in pre-pubertal and pubertal Wrestlers. Pediatric Exercise Science, 25:308-22.

[8]. Haward, B. M., Griffin, M. J. 2002. Repeatability of grip strength and dexterity tests and the effects of age and gender. Int Arch Occup Environ Health, 75:111-19.

[9]. Kolber, M. J., Cleland, J. A. 2005. Strength testing using hand-held dynamometry. Physical Therapy Reviews, 10:99-112.

[10]. Koley, S., Kaur, S. P. 2011. Correlations of handgrip strength with selected hand-arm anthropometric variables in Indian interuniversity female volleyball players. Asian Journal of Sports Medicine, 2(4):220-26

[11]. Lindstrom-Hazel, D., Kratt, A., Bix, L. 2009. Inter-ratter reliability of students using hand and pinch dynamometers. American Journal of Occupational Therapy, 63:193-97.

[12]. Mathiowetz, V., Weber, K., Volland, G., Kashman, N. 1984. Reliability and validity of grip and pinch strength evaluations. J Hand Surg [Am], 9:222-26.

[13]. Nwuga, V. 1975. Grip strength and grip endurance in physical therapy students. Arch Phys Med Rehab, 56:296-99.

[14]. Onder, G., Penninx, B. W., Lapuerta, P., Fried, L. P., Ostir, G.V., Guralnik, J. M., Pahor, M. 2002. Changes in physical performance over time in older women: the women's Health and Aging Study. J Geronol A Biol Sci Med Sci, 57:M289-93.

[15]. Peolsson, A., Hedlund, R., Oberg, B. 2001. Intra- and inter-tester reliability and reference values for hand strength. Journal of Rehabilitation Medicine, 33:36-41.

[16]. Pieterse, S., Manandhar, M., Ismail, S. 2002. The association between nutritional status and hand grip strength in older Rwandan refugees. Eur J Clin Nutr, 56:933-39.

[17]. Roberts, H. C., Denison, H. J., Martin, H. J., Patel, H. P., Syddall, H., Cooper, C., Sayer, A. A. 2011. A review of the measurement of grip strength in clinical and epidemiological studies: towards a standardised approach. Age and Ageing, 40:423-29.

[18]. Samson, M. M., Meeuwsen, I. B., Crowe, A., Dessens, J. A., Duursma, S. A., Verhaar, H. J. 2000. Relationships between physical performance measures, age, height and body weight in healthy adults. Age and Ageing, 29:235-42.

[19]. Trutschnigg, B., Kilgour, R. D., Reinglas, J., Rosenthall, L., Hornby, L., Morais, J. A., Vigano. 2008. Precision and reliability of strength (Jamar Vs Biodex handgrip) and body composition (dual-energy X-ray absorptiometry vs bioimpedance analysis) measurements in advanced cancer patients. Appl Physiol Nutr Metab, 33:1232-39.

[20]. Wang, A. Y., Sea, M. M., Ho, Z. S., Lui, S. F., Li, P. K., Woo, J. 2005. Evaluation of handgrip strength as a nutritional marker and prognostic indicator in peritoneal dialysis patients. Am J Clin Nutr, 81(1):79-86.

[21]. Yasuo, G., Daisaku, T., Nariyuki, M., Junya, S., Toshihiko, O., Masahiko, M., Yashiyuki, M. 2005. Relationship between grip strength and surgical results in rotator cuff tears. Shoulder Joint, 29:559-62. 